\title{
COMPARATIVE INVENTORY OF VEGETATION AND SOILS SURROUNDING TECK COAL LTD.'S COAL MOUNTAIN OPERATIONS
}

\author{
Michael E. Keefer, MSc, PAg \\ Randy Moody, MSc, RPBio \\ Tipi Mountain Native Plants Ltd. \\ PO Box 94, Cranbrook, BC V1C 4J6 \\ mike@keefereco.com
}

\begin{abstract}
Coal mine reclamation has historically consisted primarily of planting agronomic species on forage areas and/or to meet biomass accrual standards; in modern day reclamation a shift is occurring towards more biodiversity driven standards. This project represents a positive step in an ecosystem based approach to developing reclamation prescriptions that follow natural succession trajectories for native plant community establishment. A comparative study was implemented to examine soil and plant community characteristics on mine spoil sites and on natural reference sites to determine what native plant species and communities may be suited to establishment on ecologically comparable mine spoil sites as a reclamation treatment. A total of 22 field plots were established: 3 on spoil and 19 on reference sites. A total of 164 plant species were inventoried including 147 native, 11 introduced, and 6 agronomic species which are likely an artefact of past reclamation efforts. Sixty-seven species were identified as having high reclamation potential and are expected to be readily propagated. The soil data suggests that the mine spoils are nutritionally similar to the soils in the reference ecosystems. Recommended treatments include establishing early successional native plant communities that are developed to follow site specific successional pathways as observed near Coal Mountain Operations in reference areas.
\end{abstract}

Key Words: reclamation, mine spoil, native plants, succession

\section{INTRODUCTION}

The Elk Valley is locally known for its high diversity of both plants and plant communities, many of which thrive in landscapes that are frequently disturbed by a variety of processes. Natural disturbances include wildfire, avalanches, slope failures, floods, and grazing; these are augmented by man made disturbances such as mine exploration, mining, logging, road construction, recreational activities, livestock grazing, and the introduction of non-native species.

Success within the field of mine reclamation in BC has traditionally been measured using plant biomass as the primary metric. Such a metric is readily met with the use of agronomic grass and forb species as their seed is relatively inexpensive, proven to grow in disturbed environs, are commercially available, and the plants readily respond to fertilization. Along with agronomic plants, conifers are often planted with forestry land use objectives in mind. While this approach frequently results in good biomass metrics for the agronomic plant species, it does not create favourable conditions for biological diversity in the short term, and may not tend to direct a site to a robust native plant community that follows successional trajectories as would be seen in natural disturbances. Rather, this approach builds relatively stable agronomic plant communities that, in some instances, are resistant to the invasion of native species. The high elevation conifer plantations frequently fail to meet commercial forestry end land use objectives 
because of a variety of natural limiting conditions, including short growing season, wind and exposure. In the short term, this type of reclamation is believed to set the ecosystems off in a different successional pathway than would naturally occur making it unlikely for a native plant dominated community, comparable to what would naturally develop after a major disturbance, to re-establish. These different successional pathways may lack the kind of edaphic communities that help an optimal native forest system thrive, further delaying the ultimate restoration of the ecosystem (Richard Winder personal communication 2010). Further limiting natural plant establishment within these agronomic settings is the scale of the mine disturbance, which is often too large to rely on natural seed rain. In summary, in this setting, natural invasions are potentially hindered by high levels of competition from agronomic species, and distance from native seed sources.

Reclamation has been defined as a "planned series of activities designed to recreate the biophysical capacity of an ecosystem” (Dunster and Dunster 1996). There is a continuum from reclamation to restoration in which successful reclamation may be measured by indices such as biomass, with ecological restoration on the other end of the continuum with a metric of biodiversity and full ecosystem functioning. A component of the ecological restoration process is the "reinstatement of driving ecological processes" (Society of Wetland Scientists 2000); key to this definition is the concept of assistance. In order to provide such help it is germane to examine neighbouring native plant communities, and to employ these communities as reference sites from which to design prescriptions. A reference site is "an area comparable in structure and function to the targeted restoration site” (Staveren et al. 2006). Following this approach, reference sites and their associated plant species were used to design a proposed native plant-based restoration strategy. Though pre-mining ecological conditions can never be replicated following open pit mining, appropriate native plant communities can be initiated through carefully designed planting and seeding activities, and their development can be facilitated by mimicking appropriate ecological pathways.

Attempting to mimic the process of ecological succession is of great value in the context of rehabilitating mine spoils. This approach follows a vegetation model whereby colonizing plant communities are succeeded by more stable, steady state communities comprised mostly of native plants. The role of reference sites when employing this approach is crucial, as it is often erroneously assumed that the successional trajectory should flow from lower growth forms to a forested site. This over-simplification can be misleading, especially in the context of grassland and shrub dominated ecosystems. Within these ecosystems observed at Teck's Coal Mountain Operations (CMO), key natural processes such as fire and possibly bighorn sheep grazing have been removed. Many of these sites are currently maintained in relatively open conditions by often heavy deer and elk grazing. In the case of the CMO area, grassland type sites occurring on warm aspects were historically maintained by fire.

The concept of following natural succession in reclamation is not unique (Polster 1989, Baig 1992, Macyk 2002). However, implementing this method on coal mine spoils poses unique challenges. Mine spoils are often coarse textured with low albedo values, which often result in highly xeric conditions subject to high soil temperatures. The coarseness of spoils, clay content, moisture retention capacity, and availability of N,P,K, and S have all been shown to be ameliorated on older mine spoils (Baig 1992); 
indicating that not only does chemical and physical weathering act on spoils, but that these changes may facilitate revegetation.

It is valuable when considering ecological succession on a given site to look at approved end land use objectives, potential wildlife uses, potential natural processes and other factors. Sites which may be expected to naturally trend towards closed forest conditions may appropriately be initially restored to lower plant diversity, while sites with grassland objectives should likely have a higher emphasis on the creation of biologically diverse plant communities.

This project focussed on describing a number of plant communities surrounding CMO with an emphasis on sites that have been disturbed by either natural or man-made processes, including a few sites that had been mined, and not deliberately reclaimed. The key objective of the survey work was to develop a list of all native plant species found in the project area and examine their potential for use in mine reclamation. The data collected were also used in an analysis of what types of sites each plant species may be suited for planting in, including elevation, aspect and soil types. In future projects, this data could be modelled and used for predicting the resultant ecosystem following reclamation activities.

\section{METHODS}

Sites were selected with the goal of describing a wide variety of disturbed sites throughout the area surrounding the mine. The local knowledge of Don Sacino of the project area was instrumental in site selection and was augmented through conversations with Warn Franklin and the use of Google Earth images.

Survey work for this project was completed in September 2008 and in July 2009 by Michael Keefer and Don Sacino. Data were collected using the BC Government Ground Inspection Form (GIF), a standardized form widely used in ecosystem mapping work. Exhaustive plant species lists and estimates of percent cover were collected in plots approximately $20 \times 20 \mathrm{~m}$ in area. Geographical information was recorded using hand held GPS. At each plot a scaled digital photo was taken of a representative view of the site with a sign board and range pole. Basic terrain information was also recorded as per the GIF form. In the interests of building a baseline inventory of soils found on these sites, soil samples were collected and mixed to produce a composite of soils from within the upper horizons of each plot area and sent away for analysis.

The botanical authority for this work was the Illustrated Flora of BC, Volumes 1-8 (Douglas et al 19982002). In the interests of facilitating understanding amongst non-botanists, common names generally follow those found in Plants of Southern Interior BC (Parish et al 1996).

Data were entered into the VPro Database, an MS Access database developed by the Ministry of Forests and Range Research Branch for ecosystem mapping projects. Following data input and review, the data were extracted into MS Excel tables and were provided to a biostatistician for statistical analysis in the statistical application R 2009 v. 2.9.1. The master species list developed from the VPro database was exported to $\mathrm{R}$ for statistical analysis. 
The distribution of species according to elevation, slope and aspect was assessed with a series of boxplots, showing the range of elevation at which each of the most frequent species appeared.

Species-specific information was compiled into a master species table, including information on growth form, ecological and ethnobotanical characteristics, nursery propagation factors, and reclamation utility. Ecological and ethnobotanical characteristics were determined using Klinka et al. (1989) and Moerman (2002); nursery propagation factors were provided by Jason Meuleman (Personal Communication) of Tipi Mountain Native Plants. Reclamation potential of each species was determined by considering pioneering ability, $\mathrm{N}$ fixing ability, ubiquity, and ease of propagation.

Soil characteristics from inside the mine were compared to soil characteristics from outside the mine using principal component analysis (PCA) ordination to allow for the representation of the complex multidimensional data in a Euclidian, reduced space. Ordination allows the projection of a multidimensional dataset into two dimension diagrams whose axes are chosen to represent the largest fraction of the variability of the original multidimensional dataset (Legendre and Legendre 1998). It thus allows summarizing the relationships between plots and soil variables.

\section{RESULTS}

Vegetation

Fieldwork resulted in a total of 22 plots being recorded, with a total combined plant list of 164 species (not included here). Of these plants, six were agronomic, seven were invasive species and four were introduced and not considered invasive. It is likely that further survey work would identify a longer list of native plant species on naturally disturbed areas. Plant biomass was not recorded at plot locations; however, it was observed that many of the natural sites had low plant cover with extensive areas covered by rock. Species specific analyses was only conducted on species that occurred in at least three sample plots; resulting in 71 species being analyzed for relationships with slope, aspect, and elevation.

The distribution of plant species by elevation is shown in Figure 1 using the Latin species codes: translation of these codes is found in the original report (Keefer 2010).

Figure 1 should be considered as a guide to general elevational trends for species in the area, as opposed to being the guide on elevational requirements for the species. The original report (Keefer 2010) also illustrates the distribution of plant species by aspect, as well as the relationship between slope and plant species. 


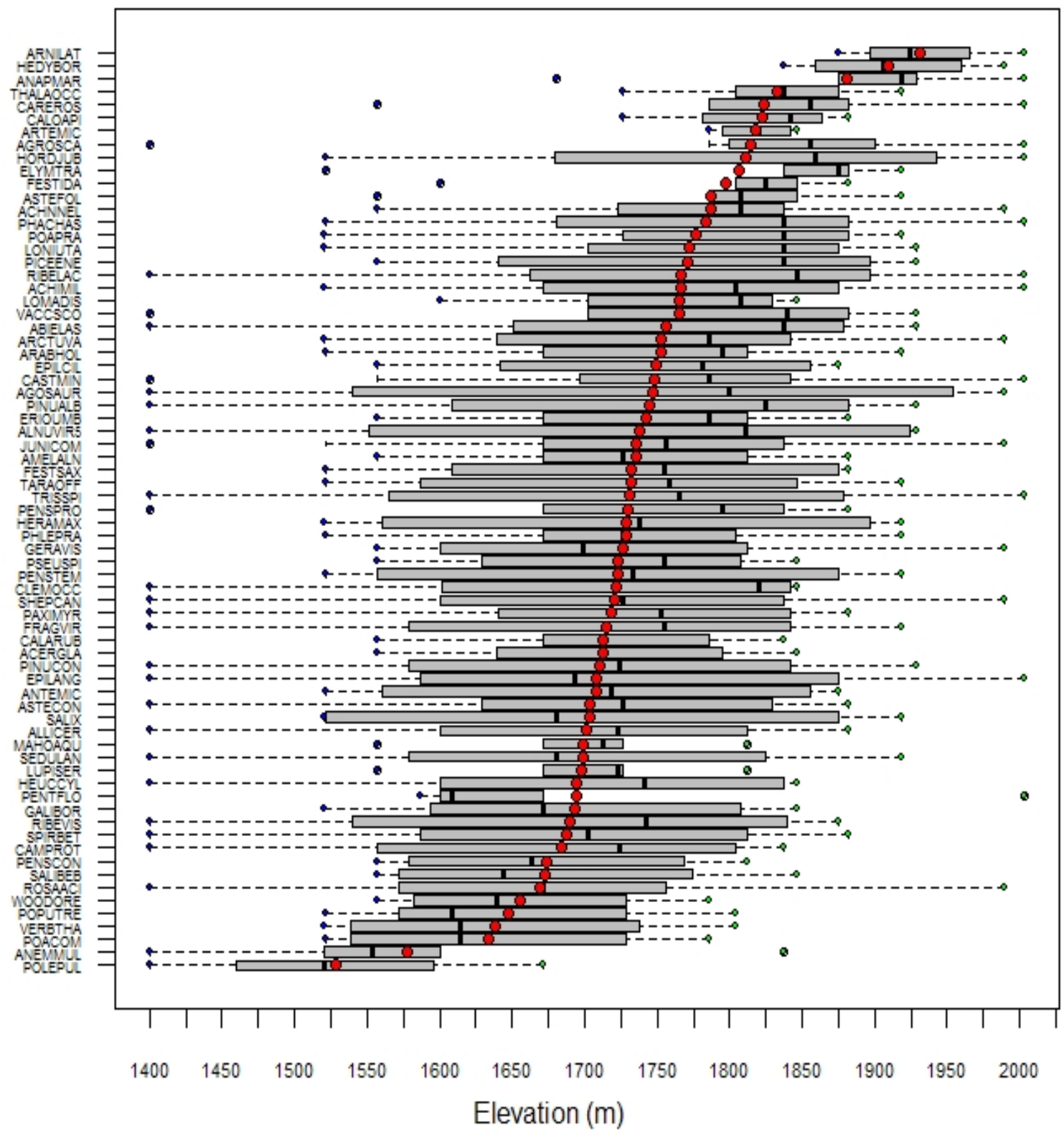

Figure 1. Distribution of 71 plant taxa by elevation at Coal Mountain. Dots within grey bars show species mean elevation, black bars are median values based on species occurrence, dots to the left and right of the grey bars show minimum and maximum elevations, and grey bars show the 25 and 75 percent quartiles. Only species occurring in $\geq 3$ plots are shown.

Of the species inventoried in the plots, 67 were identified as having high reclamation potential based on the parameters previously described (Table 1). This plant list will provide important guidance on how to incorporate native species reclamation at Coal Mountain into the overall reclamation program. 
Table 1. Species noted as having high reclamation potential.

\begin{tabular}{|c|c|c|}
\hline Latin Name & Species Code & Common Name \\
\hline Abies lasiocarpa & ABIELAS & subalpine fir \\
\hline Acer glabrum & ACERGLA & Rocky Mountain maple \\
\hline Achillia millefolium & ACHIMIL & yarrow \\
\hline Achnatherum nelsonii & ACHNNEL & Columbian needlegrass \\
\hline Agrostis scabra & AGROSCA & hair bentgrass \\
\hline Alnus viridis ssp. tenuifolia & ALNUVIR5 & mountain alder \\
\hline Amelanchier alnifolia & AMELALN & Saskatoon \\
\hline Anaphalis margaritacea & ANAPMAR & pearly everlasting \\
\hline Antenaria microphylla & ANTEMIC & rosy pussytoes \\
\hline Antenaria neglecta & ANTENEG & field pussytoes \\
\hline Apoycynum androesifolium & APOCAND & spreading dogbane \\
\hline Arctostaphyllos uva-ursi & ARCTUVA & kinickinick \\
\hline Astragalus agrestis & ASTRAGA & field milk-vetch \\
\hline Astragalus collinus & ASTRCOL & hillside milk-vetch \\
\hline Balsamhoriza sagittata & BALSSAG & arrow-leaved balsamroot \\
\hline Bromus carinatus & BROMCAR & California brome \\
\hline Calamagrostis canadensis & CALACAN & bluejoint reedgrass \\
\hline Carex microcroptera & CAREMIC & small winged sedge \\
\hline Cornus stolonifera & CORNSTO & red-osier dogwood \\
\hline Crepis nana & CREPNAN & dwarf hawksbeard \\
\hline Dryas drummondii & DRYADRU & yellow mountain-avens \\
\hline Elymus glaucus & ELYMGLA & blue wildrye \\
\hline Elymus trachycaulum & ELYMTRA & slender wheatgrass \\
\hline Eriogonum umbellatum & ERIOUMB & sulphur buckwheat \\
\hline Festuca idahoensis & FESTIDA & Idaho fescue \\
\hline Festuca saximontana & FESTSAX & Rocky Mountain fescue \\
\hline Hedysarum boreale & HEDYBOR & northern sweet-vetch \\
\hline Hedysarum sulphurescens & HEDYSUL & yellow hedysarum \\
\hline Lathyrus ochroleucus & LATHOCH & creamy peavine \\
\hline Leymus innovatus & LEYMINN & fuzzy wildrye \\
\hline Lonicera involucrata & LONIINV & black twinberry \\
\hline Lonicera utahensis & LONIUTA & Utah honeysuckle \\
\hline Lupinus sericeus & LUPISER & silky lupine \\
\hline Mahonia aquifolium & MAHOAQU & Oregon grape \\
\hline Oxytropis campestris & OXYTCAM & field locoweed \\
\hline Paxistima myrsinites & PAXIMYR & falsebox \\
\hline Phacelia hastata & PHACHAS & silverleaf phacelia \\
\hline Phacelia sericea & PHACSER & silky phacelia \\
\hline Pleum alpinum & PHLEALP & alpine Timothy \\
\hline Pinus albicaulis & PINUALB & whitebark pine \\
\hline Poa alpinum & POA ALP & alpine bluegrass \\
\hline Populus balsamifera ssp. trichocarpa & POPUBAL & black cottonwood \\
\hline Populus tremuloides & POPUTRE & trembling aspen \\
\hline Prunus virginiana & PRUNVIR & chokecherry \\
\hline Pseudoroegneria spicata & PSEUSPI & bluebunch wheatgrass \\
\hline
\end{tabular}




\begin{tabular}{|c|c|c|}
\hline Ribes laustre & RIBELAC & bristly black currant \\
\hline Ribes viscoissimum & RIBEVIS & sticky currant \\
\hline Rosa accicularis & ROSAACI & prickly rose \\
\hline Rubus ideaus & RUBUIDA & red-raspberry \\
\hline Rubus parviflorus & RUBUPAR & thimbleberry \\
\hline Salix bebbiana & SALIBEB & Bebb's willow \\
\hline Salix spp. & SALIX & willow \\
\hline Sambucus racemosa ssp. pubens & SAMBRAC & black elderberry \\
\hline Selaginella densa & SELADEN & compact selaginella \\
\hline Shepherdia canadensis & SHEPCAN & soopolallie \\
\hline Solidago canadensis & SOLICAN & Canada goldenrod \\
\hline Solidago spatulata & SOLISPA & spikelike goldenrod \\
\hline Sorbus sitchensis & SORBSIT & Sitka mountain-ash \\
\hline Symphoricarpus albus & SYMPALB & common snowberry \\
\hline Trisetum canescens & TRISCAN & nodding trisetum \\
\hline Trisetum spicatum & TRISSPI & spike trisetum \\
\hline Vaccinium membranaceum & VACCMEM & black huckleberry \\
\hline Vaccinium scoparium & VACCSCO & grouseberry \\
\hline Vahlodea atropurpurea & VAHLATR & mountain hairgrass \\
\hline Viburnum edule & VIBUEDU & highbush cranberry \\
\hline Alnus crispa & ALNUCRI & Sitka alder \\
\hline Elaeagnus commutata & ELAECOMM & Wolf willow \\
\hline
\end{tabular}

\section{$\underline{\text { Soils }}$}

The soil characteristics at the three sites inside the mine were compared to soil characteristics at reference sites outside the mine using an ordination, allowing a summary of the relationships between plots and soil variables (Figure 2). Principal component analysis (PCA) was used to allow the representation of the complex multidimensional data in a Euclidian, reduced space. A complete explanation of statistical analysis conducted on soil data can be found in the original report (Keefer 2010). Results suggest that from the perspective of soil nutrients, soils on the mine site were not more similar among themselves than to the other plots outside of the mine. Soil $\mathrm{pH}$ values had a wide range (5.8-8.4) and most sites were slightly alkaline. Nutrient analysis and base saturation were not conducted for all sites as sampling methods were altered after several samples had been submitted for testing. 


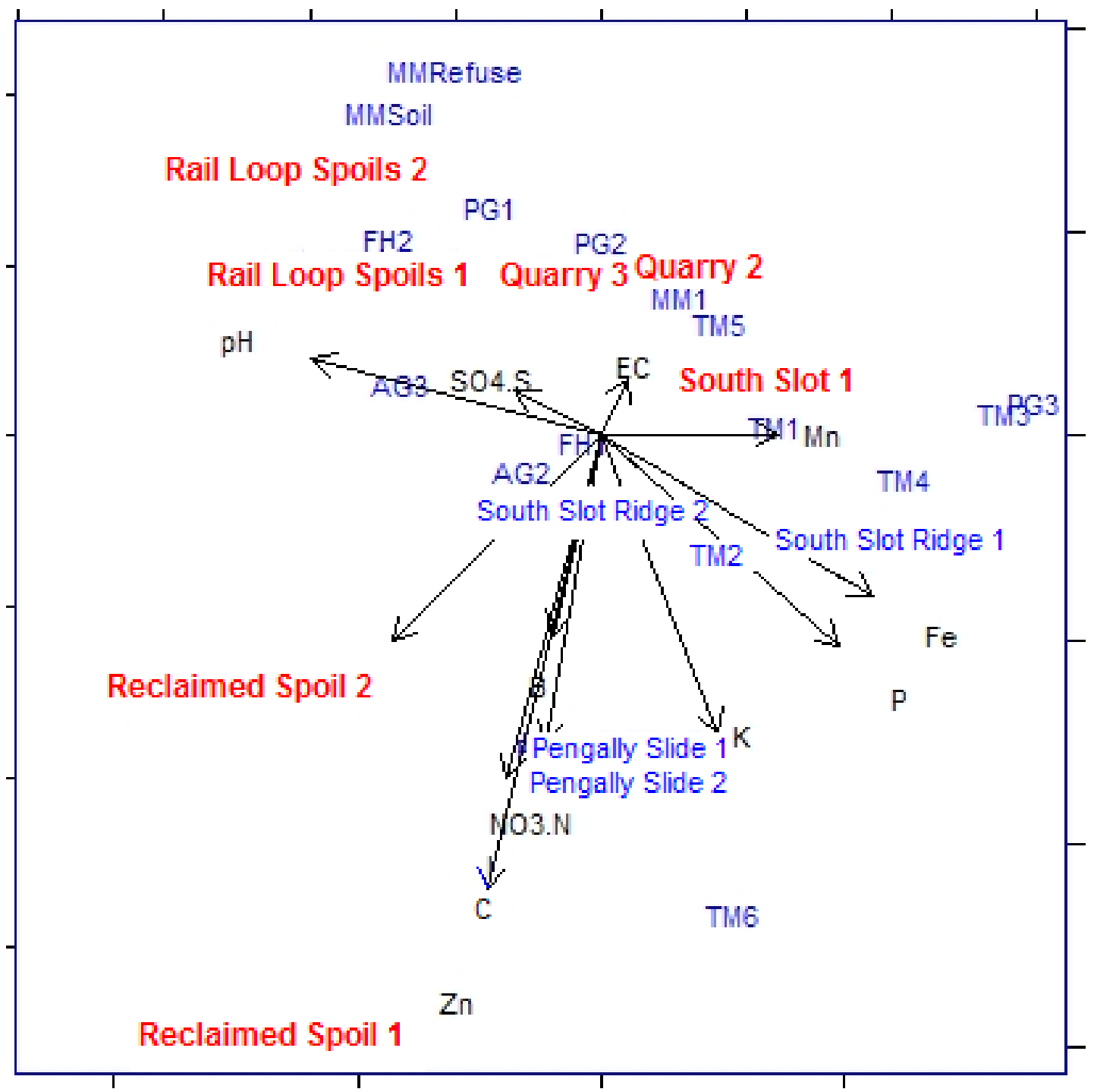

Figure 2. PCA ordination diagram showing the distribution of the plots in regard to soil variables. Axis 1 expresses 32\% and axis 2 expresses 16\% of the variation in the multivariate dataset. Plots in red were located within the mine, and plots in blue were located outside of the mine.

\section{DISCUSSION AND FUTURE WORK}

\section{$\underline{\text { Vegetation }}$}

That the vegetation inventoried on the plots outside the mine during this project was dominated by native species speaks strongly to the potential for the mine site to be effectively reclaimed to native plant communities, keeping in mind that the inventoried areas had been naturally or artificially disturbed areas with no external reclamation treatments.

Further, this suggests that there is a potential for native species to be used in reclamation programs as an alternative to agronomic species dominated treatments. It is anticipated that attempting to mimic natural succession on mine spoils will facilitate a return to stable, functioning plant communities that will meet and enhance end land use objectives. 
The analysis of elevation range occupied by the species was produced for illustrative purposes; for some species the results likely reflect typical elevation range for the species, while for others, the observed range likely differs from typical ranges due to a lack of data. An example of this is pearly everlasting only being recorded above $1875 \mathrm{~m}$. Based on knowledge of this species, this is an artefact of sampling. If sampling had been more extensive and balanced by elevation and aspect, a broader distribution would likely have been recorded; however, the purpose of this project was to explore areas with a variety of natural disturbances as opposed to examining the precise elevation and aspect preferences of the species in the CMO area.

Many of the native species inventoried are already well known for their pioneering and/or nitrogen fixing abilities. Coupled with their ecological niche within the local environment, such species are obvious choices for testing in future reclamation work. Locally, some work has already been completed regarding the utility of native legume species for reclamation (Smyth 1997).

Although many of the species identified in this study are readily available from commercial nurseries, many of the species identified as having high reclamation potential are not available. These species were neither collected in the 2009 CMO seed collection, nor are they regularly available as planting stock from commercial nurseries. These factors point to a need for future seed collection and propagation and/or direct seeding to achieve broad implementation of full scale successional reclamation strategies using the native species identified.

\section{$\underline{\text { Soils }}$}

The exploratory work on the soils within our plots suggests that the mine spoils are nutrionally similar to the soils in the reference ecosystems. Two of the spoils (Reclaimed spoil 1 and 2), both coarse coal rejects of which were seeded with agronomics and fertilized, appeared to be more different from natural soils and the other mine spoils. This may indicate that the reclamation process applied to these spoils may have resulted in these spoils deviating from a natural trajectory that may occur in untreated spoils or simply that spoils with high coal content are different.

The separation of the aforementioned reclaimed spoils from the other spoils may be attributed to inputs from the reclamation process, or it is probable that these were older soils that had been physically and chemically weathered for a greater period of time than the other spoils sampled. Baig (1992) found the available N, P, K, and S to be greater in older spoils (Baig 1992), which corresponds well with the trends observed in the spoils in this study. We speculate that soil nutrients are not more of a limitation to native plant establishment within the spoils than they are to post disturbance plant establishment outside of the spoils.

Additional tests examining soil characteristics such as soil textures should also be analyzed to further determine the similarities between the coal mine and reference sites. 


\section{$\underline{\text { Recommended Treatment Trials }}$}

It is recommended that a program be developed to test the native species recommended for reclamation based on the results of this study. Of the species inventoried, 67 were considered as high potential species for reclamation, 55 with moderate potential and 30 rated as low.

A long-term reclamation strategy would be to initiate early seral stages everywhere, but tailor plantings based on the potential for the site to advance to later successional stages. For example a site that is expected to be maintained as an early successional herb/shrub community will only be planted with early successional species; whereas, a site with a high probability to advance successionally will also include a small component of mid and late seral species to facilitate movement along successional pathways. Targeted site treatments should be predefined within the site's reclamation plan in order to ensure proper spatial distribution on a landscape level in relation to end land use objectives.

It is suggested that revegetation implementation be designed for rapid and pragmatic feedback on best practices for revegetation, rather than for peer reviewed scientific journals that require extremely high data standards and many replicates of treatments. Recommended methods may include the use of relatively few seedlings (or seed), of lesser understood species be established under a very controlled setting; whereas better understood species may be utilized at a larger scale emphasizing the known site requirements of each species. Given the different sizes, ecological amplitudes, and life histories of the plants, different methods of evaluation are recommended in order to be efficient.

For areas seeded or stocked at higher densities with small herbaceous plants or seedlings, only small areas (20m x 20m) over a range of site types are required for treatment monitoring. These are paired with nontreated controls for comparison. Species such as shrubs and trees may be planted at lower densities as they require a larger area for successful monitoring. Potential monitoring methods include fixed radius plots or belt transects. The fixed radius plots may be set up using nested plots of different radii, with different sized plots targeting different species. Likewise, the belt transect may be set up at varying widths and lengths in order to accommodate the sites, or to target different vegetation types if the plantings are mixed. In these larger areas untreated controls should be also be included. Key information to document in each research plot include site type(s), substrate, description, aspect, elevation, plant cover, and plant height.

Some of the species are already well known for their presence within mine spoils, but many have yet to be used. Three untested early seral native species (silverleaf phacelia, common yarrow and pearly everlasting) should readily establish from seed and are already present in many spoils. It is likely that low density research plantings ( $\sim 50$ stems per hectare) of these species could produce large seedbanks to colonise the fresh spoils; the results of which could easily be documented in the context of monitoring plots. A key goal with using early seral species is to produce litter on the soils that will allow for increased soil biota and nutrient cycling.

The low surface albedo of coarse coal reject (CCR) spoils may be increased through interseeding of annuals, planting cottonwood stakes, and mechanical creation of cooler microsites through terrain 
diversity or through the dumping of lighter coloured substrates on top of the CCR spoils. These site ameliorating activities may help form a bridge between initial hostile site conditions and site conditions conducive to long-term plant community development. All reclamation efforts should document the surface albedo and substrate genetics in order to determine the extent to which substrate characteristics can be correlated to plant establishment and when modifications such as soil amendments or refining species selection for a given site are warranted.

The primary recommendation from the work conducted during this project is to develop native plant community-based reclamation strategies. In doing so, it may be prudent to incorporate spoil age and characteristics into reclamation planning since the weathering of mine spoils may result in increased nutrient availability (Baig 1992). Future research trials should examine the texture and nutrient content of different aged spoils and establish research plantings accordingly.

\section{$\underline{2010 \text { Work Plan }}$}

Work being implemented in 2010 based on results from this study includes surveys at higher elevation sites (> $2000 \mathrm{~m}$ ), exploratory work on a nearby old coal mine that has been naturally reclaimed, documentation of soil biota, enhanced seed collection, biomass sampling on reference sites, and preparation for future ecosystem modelling (TEM). More detailed information on these activities can be found in the original report (Keefer 2010).

\section{CONCLUSIONS}

This small exploratory project has led to an increased list of plants suitable for reclamation of the Coal Mountain Operations. It is expected that an applied research program of testing both species and techniques will result in a large expansion of reclamation prescriptions available to the mine. Through further development of baseline information on surrounding native plant communities, it will be possible to develop guidelines that balance plant biomass and biodiversity as metrics for future mine reclamation.

Successional reclamation is not new, but our ability to implement this reclamation model has improved. In Alberta, a similar project was undertaken and created a species list comparable to that created for this project, but noted that seeds or seedlings were not commercially available to make restoration using these species a viable option (Baig 1992). The obstacles of native seed and seedling availability have been reduced thanks to the work of specialized local nurseries who specialise in propagating many of the species identified in this report.

To ensure the most appropriate and prudent use of planting stock, it is recommended that terrestrial ecosystem mapping be undertaken to compare the conditions at the Coal Mountain area with local reference sites to best identify target reclamation ecosystems and plant communities adapted to be resilient under local stressors and to achieve the desired end land use objectives. 


\section{REFERENCES}

Baig, MN. 1992. Natural revegetation of coal mine spoils in the rocky mountains of Alberta and its significance for species selection in land restoration. Mountain Research and Development. 12(3): 285-300. Available online from: JSTOR.

Douglas, George W., G.B. Straley, D.V. Meidinger, and J. Pojar. editors. 1998-2002. Illustrated Flora of British Columbia Vol. 1-8. B.C. Ministry of Environment, Lands \& Parks and B.C. Ministry of Forests. Victoria.

Dunster, J. and K. Dunster. 1996. Dictionary of Natural Resource Management. University of British Columbia Press.

Keefer, Michael E., R. Moody, T.J. Ross, A. Chapman and J. Meuleman. 2009.

CLBWORKS-2 Arrow Lakes Reservoir Revegetation Program Physical Works Report (2009). Report prepared by Keefer Ecological Services for BC Hydro. 50 pp. plus appendices.

Klinka, K. VJ. Krajina, A. Ceska, and AM. Scagel. 1989. Indicator plants of coastal British Columbia. UBC Press. Vancouver, BC. 288 pp.

Legendre, P. and L. Legendre. 1998. Numerical Ecology, Developments in Environmental Modelling 20 ( $2^{\text {nd }}$ English Edition). Elsevier Scientific Publishing Company, Amsterdam, 853 pp.

Macyk, TM. 2002. Thirty years of reclamation research in the alpine and subalpine regions near Grande Cache, Alberta. The Technical and Research Committee on Reclamation. In: Proceedings of the $26^{\text {th }}$ annual British Columbia mine reclamation symposium in Dawson Creek, BC, 2002. p 22-33.

Moerman, Daniel E. 2002. Native American ethnobotany. $4^{\text {th }}$ ed. Portland (OR): Timber Press.

Parish, Roberta, R. Coupe and D. Lloyd. 1996. Plants of the southern interior of British Columbia. BC Ministry of Forests, Lone Pine Publishing, Vancouver, BC. 462 pp.

Polster, David F. 1989. Successional reclamation in Western Canada: New light on an old subject. Paper presented at the Canadian Land Reclamation Association and American Society for Surface Mining and Reclamation conference, Calgary, Alberta, August 27-31, 1989.

Smyth, Clint R. 1997. Native legume transplant survivorship and subsequent seedling recruitment on unamended coal mine soils in the Canadian rocky mountains. Mountain Research and Development. 17(2): 145-157.

Society of Wetland Scientists. 2000. Position Paper on the Definition of Wetland Restoration.

Staveren, John van, D. Groff, and J. Goodridge. 2006. Freshwater wetlands. In: Apostol Dean, and M. Sinclair. editors. 2006. Restoring the pacific northwest: The art and science of ecological restoration in Cascadia. Island Press. 475 p. 